\title{
Sepsis is a major determinant of outcome in critically ill HIV/AIDS patients
}

\author{
André M Japiassú ${ }^{1}$, Rodrigo T Amâncio ${ }^{1}$, Emerson C Mesquita ${ }^{1}$, Denise M Medeiros ${ }^{1}$, Helena B Bernal ${ }^{2}$, \\ Estevão P Nunes², Paula M Luz², Beatriz Grinsztejn², Fernando A Bozza ${ }^{1 *}$
}

\begin{abstract}
Introduction: New challenges have arisen for the management of critically ill HIV/AIDS patients. Severe sepsis has emerged as a common cause of intensive care unit (ICU) admission for those living with HIV/AIDS. Contrastingly, HIV/AIDS patients have been systematically excluded from sepsis studies, limiting the understanding of the impact of sepsis in this population. We prospectively followed up critically ill HIV/AIDS patients to evaluate the main risk factors for hospital mortality and the impact of severe sepsis on the short- and long-term survival.

Methods: All consecutive HIV-infected patients admitted to the ICU of an infectious diseases research center, from June 2006 to May 2008, were included. Severity of illness, time since AIDS diagnosis, CD4 cell count, antiretroviral treatment, incidence of severe sepsis, and organ dysfunctions were registered. The 28-day, hospital, and 6-month outcomes were obtained for all patients. Cox proportional hazards regression analysis measured the effect of potential factors on 28-day and 6-month mortality.

Results: During the 2-year study period, 88 HIV/AIDS critically ill patients were admitted to the ICU. Seventy percent of patients had opportunist infections, median CD4 count was 75 cells $/ \mathrm{mm}^{3}$, and $45 \%$ were receiving antiretroviral therapy. Location on a ward before ICU admission, cardiovascular and respiratory dysfunctions on the first day after admission, and the presence of severe sepsis/septic shock were associated with reduced 28-day and 6-month survival on a univariate analysis. After a multivariate analysis, severe sepsis determined the highest hazard ratio (HR) for 28-day (adjusted HR, 3.13; 95\% Cl, 1.21-8.07) and 6-month (adjusted HR, 3.35; 95\% Cl, 1.42-7.86) mortality. Severe sepsis occurred in $44(50 \%)$ patients, mainly because of lower respiratory tract infections. The survival of septic and nonseptic patients was significantly different at 28-day and 6-month follow-up times (logrank and Peto test, $P<0.001$ ).
\end{abstract}

Conclusions: Severe sepsis has emerged as a major cause of admission and mortality for hospitalized HIV/AIDS patients, significantly affecting short- and longer-term survival of critically ill HIV/AIDS patients.

\section{Introduction}

The long-term survival of patients with human immunodeficiency virus (HIV) has markedly improved since the introduction of highly active antiretroviral therapy (HAART). UNAIDS/WHO estimated at 33.4 million the number of people living with HIV in December 2008 [1]. It is expected that this number will continue to grow, in particular in third-world urban centers. Recent studies have analyzed HIV/AIDS critically ill patients' characteristics, especially comparing pre- and post-

\footnotetext{
* Correspondence: bozza.fernando@gmail.com

'Intensive Care Unit, Instituto de Pesquisa Clínica Evandro Chagas, Fundação

Oswaldo Cruz, Av Brasil 4365, Rio de Janeiro, RJ, 21040-360, Brazil

Full list of author information is available at the end of the article
}

HAART eras, with emphasis on causes of admission and risk factors for mortality [2-7]. A large cohort of HIV critically ill patients showed that sepsis is among the causes of ICU admissions with increasing incidence, contrary to the decreasing trend observed for acute respiratory insufficiency and Pneumocystis jiroveci pneumonia [8]. Other studies have shown that bacterial infection is becoming increasingly prevalent in patients with HIV admitted to the ICU, irrespective of HAART use [9-11]. However, severe sepsis has not been systematically studied with respect to its prevalence during the ICU stay, microbiologic and organ-dysfunction characteristics, and impact on the outcome.

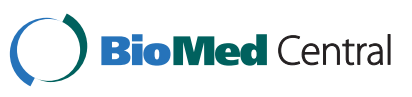

C 2010 Japiassú et al; licensee BioMed Central Ltd. This is an open access article distributed under the terms of the Creative Commons Attribution License (http://creativecommons.org/licenses/by/2.0), which permits unrestricted use, distribution, and reproduction in any medium, provided the original work is properly cited. 
Epidemiologic studies have shown that a fraction of $1 \%$ to $10 \%$ of the sepsis patients are composed of individuals with HIV/AIDS, according to regional differences in the prevalence of HIV infection and ICU admission practices [12-19]. Recently, analysis of a large United States database of septic hospitalized patients showed that the septic HIV patients have lower rates of ICU admission compared with non-HIV groups [20].

Despite the significant increases in survival and quality of life, HIV/AIDS patients have been systematically excluded from sepsis studies, limiting the understanding of the impact of sepsis in this population. To date, few studies have assessed prospectively the determinants of survival of critically ill HIV/AIDS patients.

In this study, we prospectively followed up HIV/AIDS critically ill patients to evaluate the key factors related to outcome, with emphasis on impact of severe sepsis on the short- and long-term survival.

\section{Materials and methods \\ Design and setting}

This prospective cohort study was conducted at the ICU of the Instituto de Pesquisa Clínica Evandro Chagas (IPEC), Fundação Oswaldo Cruz, Rio de Janeiro, Brazil. IPEC has provided care to HIV/AIDS patients in Rio de Janeiro since 1986 and, currently, more than 2,000 adult patients are actively followed up at the HIV/AIDS clinic.

At our institution, only patients for whom potentially lifespan-extending treatment is available are usually considered for ICU admission. Critically ill unstable patients with indications for intensive care and monitoring and/ or need for immediate procedures or interventions are eligible for ICU admission. Treatment-limitation decisions are taken when patients do not recover from acute illness despite intensive care, or when control of the baseline condition has not been achieved. These decisions are shared by the ICU team, HIV/AIDS specialist, and family members, based on local practices [21].

The study was supported by institutional funds. The institutional review board approved the study and waived the need for informed consent. The conduct of the study did not interfere with patient-management decisions.

\section{Participants, data collection, and definitions}

All consecutive HIV-infected patients admitted to the ICU from June 2006 to May 2008 were included in this study. AIDS cases and the occurrence of AIDS-defining diseases were set by the Centers for Disease Control and Prevention (CDC) definitions, and HAART was initiated when the CD4 cell count was below 200350 cells $/ \mathrm{mm}^{3}$ [22]. Time since AIDS diagnosis was calculated from AIDS onset until ICU admission. Recent AIDS onset was defined as that occurring 2 months or less before admission. The CD4 cell count was considered when obtained within 3 months of ICU admission or measured during the first week of ICU entry. HAART was defined as the regular use of at least two nucleoside reverse transcriptase inhibitors (NRTI) plus a protease inhibitor (PI) or a nonnucleoside reverse transcriptase inhibitor (NNRTI) or a PI and an NNRTI in combination [20]. As adherence is a major component on HIV treatment efficacy, it is always checked and noted on the patient's medical charts at our institution.

In case of multiple ICU admissions, only the first one was considered. ICU causes of admission were divided into acute respiratory insufficiency, sepsis, severe neurologic disturbances, heart disease, complications of solid organ or hematologic neoplasia, metabolic disturbance, and gastrointestinal complications. Readmissions were defined for patients returning to the ICU during the same hospitalization.

A standardized data-entry form was created for the collection of demographic data, main admission diagnosis, opportunistic infections, comorbidities, location before ICU admission (emergency room, ward, or other hospital), laboratory results based on computerized laboratory records review, ICU, and hospital length of stay. The following variables were collected during the first day of the ICU stay: expanded Simplified Acute Physiology Score (SAPS) II $[23,24]$, Sequential Organ Failure Assessment (SOFA) score [25], and use of vasopressor agents. Performance Status (PS) was calculated based on patient or surrogate information [26]. During the ICU stay, the need for mechanical ventilation for more than 24 hours, use of renal-support devices, development of shock (use of vasopressor agent to maintain mean arterial pressure higher than $70 \mathrm{~mm} \mathrm{Hg}$ ) and acute lung injury (defined as $\mathrm{PaO}_{2} / \mathrm{FiO}_{2}$ ratio less than 300) were also recorded.

Sepsis definitions were based on the ACCP/SCCM Consensus Conference [27]; sepsis was present if there was a presumed or confirmed infection, associated with at least two of the following: tachycardia $>90$ beats/min; tachypnea $>30$ cycles/min (or hypocapnia $<32 \mathrm{~mm} \mathrm{Hg}$ ); fever $\left(>38^{\circ} \mathrm{C}\right)$ or hypothermia $\left(<36^{\circ} \mathrm{C}\right)$; and leukocytosis $\left(>12,000 / \mathrm{mm}^{3}\right)$ or leukopenia $\left(<4,000 / \mathrm{mm}^{3}\right)$ or the presence of more than $10 \%$ immature forms. Severe sepsis was defined if any organ dysfunction, sepsis-induced hypotension, or elevated serum lactate levels were present. Septic shock was defined as sepsis with hypotension that persisted after adequate infusion of fluids and the need for vasopressor agents.

Infections were classified as community acquired or nosocomial, according to the cutoff time point $48 \mathrm{~h}$ of hospital admission. Definitions of lower pulmonary tract infection, bloodstream infection, and urinary tract infection were made by following the CDC definitions [28]. 
Appropriate biologic material was sampled from suspected sites of infection. Microbiologic data were collected and analyzed according to the local Infection Control Committee.

\section{Statistical analysis}

Continuous variables were summarized as medians and interquartile ranges. We compared the distribution of continuous variables by using the $t$ test, and of categoric variables by using the $\chi^{2}$ test. We calculated the KaplanMeier survival function stratified by sepsis. The log-rank and Peto tests were used to evaluate whether the estimated survival functions were significantly different by strata. Two outcomes were of interest: mortality within 28 days and 6 months from entry to the ICU. We used Cox proportional hazards regression analysis to measure the effect of sepsis, as well as other factors, on 28-day and 6-month mortality. We also estimated the effect of sepsis while controlling for potential confounders such as age, time since AIDS diagnosis, HAART, location before ICU, and cardiovascular and respiratory dysfunctions, in a multivariate model. The CD4 cell count was not included on the multivariate model because of the heterogeneity of the period of data collection (within 3 months of ICU admission or during the first week of ICU entry). The proportionality assumption in Cox's regression was evaluated by the estimating the correlation between survival time and Shoenfeld's standardized residuals. We used the statistical software $\mathrm{R}$, version 2.9 [29] for all statistical analysis.

\section{Results}

\section{Patient characteristics}

During the 2-year study period, 437 HIV-positive patients were admitted to the hospital, and 101 patients became critically ill. However, 13 patients were not considered for life-sustaining measures and died in the hospital ward. One hundred seven ICU admissions of 88 patients were recorded. We analyzed only the first ICU admission of each of these 88 patients; their characteristics are shown in Table 1. In brief, the median age was 40 years, with a male predominance $(76 \%)$. The median CD4 cell count was 75 (interquartile range, 32 to 227) cells $/ \mathrm{mm}^{3}$. The median time since AIDS diagnosis was 40 months. Twenty-five patients (28\%) had recently been diagnosed with AIDS; 40 patients (45\%) were adherent to HAART, and the remaining $27 \%$ had irregular use of HAART. The percentage of patients using the three drug classes was as follows: NRTI (97\%), PI (67\%), and NNRTI (35\%). HAART use did not affect hospital survival (50\% mortality for HAART and non-HAART subjects). Patients not using HAART were younger (37 versus 43 years; $P=0.03$ ), had more opportunistic
Table 1 Demographics, HIV/AIDS characteristics, and causes of admission to ICU of all patients

\begin{tabular}{ll}
\hline & Patients $(\boldsymbol{n}=\mathbf{8 8})$ \\
\hline Age (years) & $40(31-47)$ \\
Male gender & $67(76 \%)$ \\
Time since AIDS diagnosis (months) & $40(2-90)$ \\
Recent AIDS diagnosis & $25(28 \%)$ \\
CD4 cell count (per $\left.\mathrm{mm}^{3}\right)$ & $75(32-227)$ \\
HAART use & $40(45 \%)$ \\
Cause of admission & \\
Acute respiratory failure & $26(29 \%)$ \\
Coma/torpor & $20(23 \%)$ \\
Sepsis & $18(20 \%)$ \\
Decompensated heart disease & $9(10 \%)$ \\
Gastrointestinal diseases & $6(7 \%)$ \\
Metabolic disturbance & $5(6 \%)$ \\
High-grade lymphoma & $4(5 \%)$ \\
\hline
\end{tabular}

Continuous values are shown as median and interquartile interval. AIDS, acquired immunodeficiency syndrome; ICU, intensive care unit; HAART, highly active antiretroviral therapy.

infections (83\% versus 55\%; $P<0.01)$, and had less time since AIDS diagnosis (3.5 versus 68.5 months; $P<0.01$ ).

Acute respiratory failure was the cause of ICU admission for $29 \%$ of the patients, caused by bacterial pneumonia $(n=10)$, Pneumocystis jiroveci pneumonia $(n=$ $8)$, tuberculosis $(n=6)$, and cardiogenic pulmonary edema $(n=2)$. Severe neurologic complications were the cause of ICU admission in 20 patients $(23 \%)$, and severe sepsis was present in 18 patients $(20 \%)$. Other causes of ICU admission were decompensated heart disease $(n=9)$, gastrointestinal complications $(n=6)$, metabolic dysfunction secondary to renal dysfunction or lactic acidosis related to drug adverse effects $(n=5)$, and complications of high-grade non-Hodgkin lymphoma $(n=4)$ (Table 1$)$. Sixty-two patients $(70 \%)$ had at least one opportunistic infection; $P$. jiroveci pneumonia and neurotoxoplasmosis were the most frequent opportunistic infections.

\section{In-hospital mortality}

The observed in-hospital mortality during the study period was $49 \%$. We compared the characteristics of patients who survived until the hospital discharge with those of patients who did not. Patients with non-Hodgkin lymphoma and gastrointestinal complications had a worse outcome (mortality, $100 \%$ and $83 \%$, respectively), whereas patients initially seen with acute respiratory failure, neurologic disorders, and sepsis had moderate mortality rates $(46 \%, 45 \%$, and $50 \%$, respectively). SAPS II (54 versus 44 points; $P<0.001)$ and SOFA score on day 1 (7 versus 4 points, $P<0.001$ ) were significantly higher for nonsurvivors (Table 2). Early shock (use of vasopressor 
Table 2 Comparison of patients according to hospital survival

\begin{tabular}{lll}
\hline & $\begin{array}{l}\text { Survivors } \\
(\boldsymbol{n}=\mathbf{4 5})\end{array}$ & $\begin{array}{l}\text { Nonsurvivors } \\
(\boldsymbol{n}=\mathbf{4 3})\end{array}$ \\
\hline Age (mean \pm SD) & $42(35-50)$ & $38(29-46)$ \\
Male gender (\%) & $36(80 \%)$ & $31(72 \%)$ \\
Location before ICU (ward, \%) & $24(53 \%)$ & $29(67 \%)$ \\
Performance status 3 or 4 & $1(0-2)$ & $2(1-3)$ \\
CD4 count <50 mm ${ }^{3}$ (\%) & $20(44 \%)$ & $21(49 \%)$ \\
Length of time from AIDS diagnosis & $39(2-92)$ & $50(2-85)$ \\
Recent (<3 months) AIDS diagnosis & $13(29 \%)$ & $13(30 \%)$ \\
HAART use & $20(44 \%)$ & $20(46 \%)$ \\
SAPS II expanded (points) & $44(37-54)$ & $54(46-67)^{\mathrm{b}}$ \\
SOFA D1 (points) & $4(1-7)$ & $7(4-10)^{\mathrm{b}}$ \\
Mechanical ventilation & $17(38 \%)$ & $36(84 \%)^{\mathrm{b}}$ \\
Use of vasopressors on day 1 & $6(13 \%)$ & $15(30 \%)^{\mathrm{a}}$ \\
Renal support & $3(7 \%)$ & $13(30 \%)^{\mathrm{b}}$ \\
Severe sepsis/septic shock (\%) & $15(33 \%)$ & $29(67 \%)^{\mathrm{b}}$ \\
ICU length of stay (days) & $9(5-17)$ & $10(4-14)$ \\
Hospital length of stay (days) & $24(12-58)$ & $15(10-24)^{\mathrm{a}}$ \\
\hline ADS, acquired immunodficincy syndrome
\end{tabular}

AIDS, acquired immunodeficiency syndrome; ICU, Intensive Care Unit; HAART, highly active anti-retroviral Therapy; SAPS, Simplified Acute Physiology Score; SOFA, Sequential Organ Failure Assessment. Significant differences are shown as ${ }^{\mathrm{a}} P<0.05 ;{ }^{\mathrm{b}} P<0.01$

agents in the first $24 \mathrm{~h}$ since admission) was more common in nonsurvivors (30\% versus $13 \% ; P<0.05)$. Nonsurvivors used more life-support devices, such as mechanical ventilation $(84 \%$ versus $38 \% ; P<0.01)$ and renal support therapy ( $30 \%$ versus $7 \% ; P<0.01)$. Severe sepsis or septic shock was observed with higher frequency for the nonsurvivor group $(67 \%$ versus $33 \%$; $P<0.01)$. Other demographic characteristics such as age, gender, admission from emergency or ward, and Performance Status were similar in the two groups. No statistical difference was noted between the two groups regarding CD4 cell count, time since AIDS diagnosis, and HAART use.

\section{Severe sepsis in HIV/AIDS patients}

Forty-four patients (50\%) had severe sepsis at ICU admission or during the ICU stay. In comparison with nonsepsis patients, sepsis patients were more likely to come from wards $(75 \%$ versus $45 \% ; P<0.01)$, spent more time in the ICU (11 versus 7 days; $P=0.03$ ), were more severely ill (SAPS II, 56 versus 44 points; $P<$ 0.001 ; had SOFA on day 1,7 versus 3 points; $P<0.001$ ), and needed mechanical ventilation more often $(86 \%$ versus $34 \% ; P<0.001)$. We did not observe differences in CD4 cell count or time since AIDS diagnosis between septic and nonseptic groups. Hospital mortality was significantly higher in septic when compared to nonseptic patients $(66 \%$ versus $34 \% ; P=0.002)$. Lung was the most common site of infection (52\%), followed by primary bloodstream infections (38\%), venous catheter-
Table 3 Site of infection and microbiologic data of septic shock AIDS patients

\begin{tabular}{ll}
\hline Site of infection & $\boldsymbol{n}$ \\
\hline Pulmonary & $23(52 \%)$ \\
Primary bacteremia & $17(38 \%)$ \\
Venous catheter-related infection & $3(7 \%)$ \\
Urinary tract infections & $1(3 \%)$ \\
\hline Microbiology of infection & $\mathbf{N}$ \\
\hline Pseudomonas aeruginosa & $10(23 \%)$ \\
Klebsiella pneumoniae & $6(13 \%)$ \\
Mycobacterium tuberculosis & $6(13 \%)$ \\
Enterobacter sp. & $5(11 \%)$ \\
Staphylococcus aureus & $5(11 \%)$ \\
Staphylococcus negative-coagulase & $4(9 \%)$ \\
Escherichia coli & $3(7 \%)$ \\
Acinetobacter calcoaceticus & $3(7 \%)$ \\
Serratia marcescens & $3(7 \%)$ \\
Other & $5(11 \%)$ \\
\hline
\end{tabular}

related bacteremia (7\%), and urinary tract infections (3\%) (Table 3). Nosocomial infections were the source of sepsis in $90 \%$ of the cases in our cohort. Microbiology of infections was mostly composed of gram-negative rods, such as Pseudomonas aeruginosa (10), Klebsiella pneumoniae (six), Enterobacter sp. (five), Escherichia coli (three), Acinetobacter sp. (three), Serratia marcescens (three), and Staphylococcus sp. (nine). Mycobacterium tuberculosis was the etiologic agent of severe sepsis in six (14\%) patients. There were also single cases of S. maltophilia, C. difficile, C. freundi, B. cepacia, and Candida sp. Bacteremia was detected in $43 \%$ (19) of the sepsis patients, irrespectively of the site of infection.

\section{The 28-day and 6-month survival}

By using Cox proportional hazards regression, we estimated that the hazard of death at 28 days for sepsis patients was 4 times higher than that for nonsepsis patients (HR, 4.17; 95\% CI, 1.96 to 8.90). Other factors associated with an increased hazard of death at 28 days were being in a hospital ward before entry to the ICU, and cardiovascular and respiratory dysfunctions (Table 4). The effect of sepsis on 28-day mortality was even stronger in the multivariate model, when controlling for confounding factors. The adjusted hazard of death at 28 days was almost threefold higher (HR, 3.13; 95\% CI, 1.21 to 8.07) for sepsis patients compared with nonsepsis patients when controlling for age, time since AIDS diagnosis, HAART, location before ICU, and cardiovascular and respiratory dysfunctions. When considering 6-months of follow-up, sepsis also determined the highest hazard of death in both the crude (HR, 3.25; 95\% CI, 1.75 to 6.16 ) and adjusted (HR, 3.35; 95\% CI, 1.42 to 7.86 ) analysis (Table 4 ). The survival expectation of sepsis and nonsepsis patients was 
Table 4 Crude and adjusted hazard ratios (HRs) and 95\% confidence intervals for factors associated with 28-day and 6-month mortality, as estimated by using Cox proportional hazards regression

\begin{tabular}{|c|c|c|c|c|}
\hline & \multicolumn{2}{|c|}{ 28-Day mortality } & \multicolumn{2}{|c|}{ 6-Month mortality } \\
\hline & $\begin{array}{l}\text { Crude HR } \\
(95 \% \mathrm{Cl})\end{array}$ & Adjusted HR (95\% Cl) & $\begin{array}{l}\text { Crude HR } \\
(95 \% \mathrm{Cl})\end{array}$ & Adjusted HR (95\% Cl) \\
\hline Age ( $<40$ years $)$ & $\begin{array}{l}1.96 \\
(0.99-3.89)\end{array}$ & & $\begin{array}{l}1.52 \\
(0.84-2.77)\end{array}$ & \\
\hline Location before ICU (ward) & $\begin{array}{l}2.28^{\mathrm{a}} \\
(1.10-4.73)\end{array}$ & & $\begin{array}{l}1.93^{\mathrm{a}} \\
(1.02-3.64)\end{array}$ & \\
\hline Cardiovascular dysfunction & $\begin{array}{l}2.97^{\mathrm{a}} \\
(1.23-7.13)\end{array}$ & & $\begin{array}{l}2.12^{\mathrm{a}} \\
(1.05-4.30)\end{array}$ & \\
\hline Respiratory dysfunction & $\begin{array}{l}2.21^{\mathrm{a}} \\
(1.01-4.86)\end{array}$ & & $\begin{array}{l}1.58 \\
(0.82-3.02)\end{array}$ & \\
\hline Severe sepsis/Septic shock & $\begin{array}{l}4.17^{\mathrm{b}} \\
(1.96-8.90)\end{array}$ & $\begin{array}{l}3.13^{b} \\
(1.21-8.07)\end{array}$ & $\begin{array}{l}3.25^{\mathrm{b}} \\
(1.75-6.16)\end{array}$ & $\begin{array}{l}3.35^{\mathrm{b}} \\
(1.42-7.86)\end{array}$ \\
\hline Time since AIDS diagnosis ( $<60$ days) & $\begin{array}{l}0.96 \\
(0.46-2.00)\end{array}$ & & $\begin{array}{l}0.95 \\
(0.49-1.84)\end{array}$ & \\
\hline HAART & $\begin{array}{l}1.31 \\
(0.68-2.52)\end{array}$ & & $\begin{array}{l}1.21 \\
(0.67-2.18)\end{array}$ & \\
\hline
\end{tabular}

AIDS, acquired immunodeficiency syndrome; ICU, Intensive Care Unit; HAART, highly active anti-retroviral therapy. Significant differences are shown as ${ }^{\text {a }} P<0.05$; ${ }^{\mathrm{b}} P<0.01$. Adjusted HR includes adjustments for age, CD4 count, time since AIDS diagnosis, HAART, location before ICU, and cardiovascular and respiratory dysfunctions.

significantly different both at 28-day and 6-month followup time points (Figure 1, $P$ values for log-rank and Peto tests $<0.001$ ) (Figure 1 ). No significant difference of 28 -day or 6-month mortality was retrieved when on-admission or ICU-acquired severe sepsis was analyzed separately. When

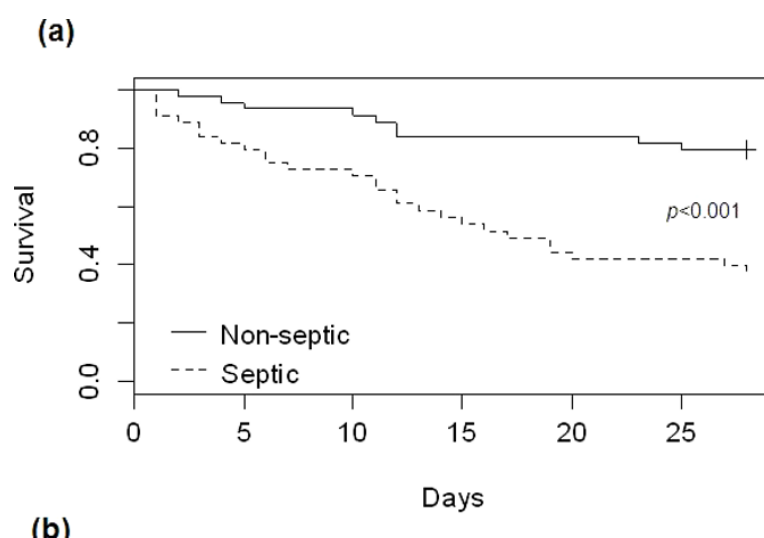

(b)

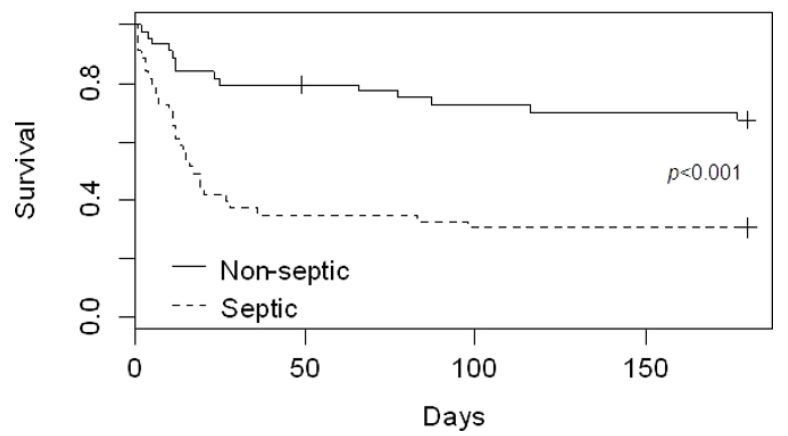

Figure 1 Kaplan-Meier plot of survival up to 28 days (top) and 6 months (bottom) of sepsis and nonsepsis AIDS patients admitted to ICU comparing follow-up periods, we noticed that, although the effect of sepsis was stronger during 28-day follow-up, it remained significant at 6 months.

\section{Discussion}

The improvement of HIV/AIDS management has led to changes in the observed clinical manifestations and outcomes of these patients in critical care units, with a decreasing trend in admissions due to opportunistic infections, whereas an opposing trend has been observed for other infectious and metabolic diseases [30]. Severe sepsis has emerged as a common cause of hospital admission for those living with HIV/AIDS [2,8,31]. In this prospective study, we demonstrated that severe sepsis is the main risk factor for hospital mortality in a cohort of HIV/AIDS critically ill patients.

Sepsis-related mortality was increased in both shortand longer-term follow-up. Indeed, sepsis patients had significantly higher in-hospital mortality than did nonsepsis patients. Severe sepsis was strongly associated with worse outcomes and was caused by bacterial infections, mainly of nosocomial origin. Nosocomial infections appear to be more common in patients with acquired AIDS compared with those not HIV infected [32]. Nosocomial infections have been associated with immunosuppression level, prior antibiotic use, and greater exposure to invasive devices such as intravenous catheters [33]. The CD4 cell count in our cohort was very low, and this could be associated with greater use of antibiotics for opportunistic infections prophylaxis or for treatment of bacterial infections contributing to a high rate of antibiotic resistance and, consequently, the development of nosocomial infection. 
Pneumonia and bloodstream infections were the main sites of infections for almost all sepsis patients, and hospital-acquired bacteria composed the major part of the microbiology of severe infections. Lower-tract respiratory infection was also the main site of infection in two other studies [34,35]. Additionally, a high incidence of nosocomial bacteremia occurred in our cohort (43\%). Bloodstream infections can negatively affect HIV/AIDS patients' outcomes [33,36-39]. In general, the microbiology of the HIV/AIDS sepsis patients was similar to that reported in non-HIV-infected patients. We observed a predominance of gram-negative and gram-positive bacteria, but also Mycobacterium tuberculosis, which was the main pathogen associated with severe sepsis in five of 44 patients. Tuberculosis, which is highly prevalent in developing countries, has been found to cause bacteremia in AIDS patients [36,40-44].

The development of organ dysfunctions was analyzed as a possible contribution to hospital mortality. In our study, cardiovascular and respiratory dysfunctions increased the hazards of death, especially in the short term. Respiratory dysfunction is closely associated to mechanical ventilation use and the presence of severe sepsis. Cardiovascular dysfunction could also be related to the presence of shock and the use of vasoactive agents, which are more frequent in sepsis patients. Use of mechanical ventilation $[3,5,31,45,46]$, higher APACHE II or SAPS II scores $[2,31,45,46]$, use of HAART during the ICU stay [45], and opportunistic infections $[3,5,46]$ have been found to affect hospital mortality in a heterogeneous group of studies. Low CD4 cell counts, time since AIDS diagnosis, HAART treatment, or AIDS stage of disease, conversely, were not identified as risk factors for mortality in the post-HAART era $[4,6,46]$.

In our cohort, almost $30 \%$ of patients had a recent AIDS diagnosis and were HAART naive, and an additional $16 \%$ of the patients were noncompliant HAART users. We found that these groups, who correspond to almost $50 \%$ of the patients in our study, were not subject to higher hospital mortality. Recent data has shown a greater impact of ICU care rather than HIV/AIDS management as major risk factors for death. Ventilatory management with lower tidal volumes was shown to be protective against mortality due to acute lung injury in critically ill HIV patients [47].

The main contribution of our study relies on the fact that sepsis is the most important risk factor for mortality in patients with HIV/AIDS admitted to the ICU. Other studies have not evaluated the diagnosis of severe sepsis or septic shock as an independent variable on survival analysis, whereas they gave greater emphasis to the presence of opportunistic infections or immunosuppression surrogates (CD4 cell count or viral load). Additionally, it provides new information on the microbiology of sepsis of the HIV/AIDS population, highlighting the occurrence of nosocomial severe infections and the great impact of sepsis on 1- and 6-month survival; second, confirming that CD4 the T-cell count, the HIV RNA level, and other HIV/AIDS variables were not predictive of 30-day and 6month outcomes.

Otherwise, our study has limitations. The study was conducted in a single center specializing in HIV/AIDS patients care, lessening a greater generalizability; and a multicenter study is needed to confirm our findings regarding the effects of severe sepsis on HIV/AIDS critically ill patients. Although no prospective comparison was made with a cohort without HIV, similarities exist in the microbiology of infections and incidence of organ dysfunctions with the non-HIV/AIDS population reported in the literature $[20,48,49]$. Future studies are necessary to evaluate the long-term effects of sepsis on quality of life and on functional capacity.

Finally, although international efforts sought to reduce sepsis mortality, increased survival has not been observed in low- and middle-income countries (LMICs) [18,50-53]. New strategies to reduce the impact of sepsis, especially in LMICs, are timely. Those strategies should be able to deal with specific subgroups of patients, including the HIV/AIDS population. In this setting, the prevention of both nosocomial and community-acquired infections should be incorporated into sepsis guidelines as a cost-effective measure for LMICs.

\section{Conclusions}

We demonstrated that severe sepsis is the main risk factor for hospital mortality in our cohort, significantly affecting short- and longer-term survival of HIV/AIDS critically ill patients. Mortality was shown to be more dependent on critically illness factors such as the presence of sepsis and the severity of organ dysfunction than on the HIV/AIDS-related characteristics, such as the level of immunodeficiency, use of HAART, or time since AIDS diagnosis. A high level of suspicion related to sepsis diagnosis coupled with initiatives related to nosocomial infection and sepsis prevention could contribute to decrease mortality in critically ill HIV/AIDS patients.

\section{Key messages}

- Sepsis is the most important risk factor for mortality in HIV/AIDS patients admitted to ICUs, affecting short- and longer-term survival. HIV/AIDS variables, such as CD4 T-cell count and HIV RNA level, play a secondary role for the prognosis of critically ill HIV/AIDS patients.

- A high level of suspicion related to sepsis diagnosis coupled with initiatives related to nosocomial 
infection and sepsis prevention could contribute to decrease mortality in critically ill HIV/AIDS patients.

\begin{abstract}
Abbreviations
ACCP/SCCM: American College of Chest Physicians/Society of Critical Care Medicine; APACHE: Acute Physiology and Chronic Health Evaluation Score; CD4: cluster of differentiation 4; HAART: Highly Active Antiretroviral Therapy; HIV/AIDS: human immunodeficiency virus/acquired immunodeficiency syndrome; ICU: intensive care unit; NNRTI: nonnucleoside reverse transcriptase inhibitor; NRTI: nucleoside reverse transcriptase inhibitor; PI: protease inhibitor; PS: performance status; SAPS: Simplified Acute Physiology Score; SOFA: Sequential Organ Failure Assessment.
\end{abstract}

\section{Acknowledgements}

$F A B$ and $B G$ are research scholars from CNPq and FAPERJ. The authors thank Dr. Valdiléa Veloso (Instituto de Pesquisa Clínica Evandro Chagas, Rio de Janeiro, Brazil) for the institutional support.

\section{Author details}

${ }^{1}$ Intensive Care Unit, Instituto de Pesquisa Clínica Evandro Chagas, Fundação Oswaldo Cruz, Av Brasil 4365, Rio de Janeiro, RJ, 21040-360, Brazil. ${ }^{2}$ HIV/AIDS Research Centre, Instituto de Pesquisa Clínica Evandro Chagas, Fundação Oswaldo Cruz, Av Brasil 4365, Rio de Janeiro, RJ, 21040-360, Brazil.

\section{Authors' contributions}

All authors made substantial contribution to the study design and methods. $A M J, D M M$, and FAB conceived of the study. AMJ, RTA, ECM, and HBB collected clinical and microbiologic data. PML performed the data analysis. $A M J, P M L$, and FAB drafted the manuscript, and DMM, EPN, and BG critically revised it for important intellectual content. All authors read and approved the final version of the manuscript.

\section{Competing interests}

The authors declare that they have no competing interests.

Received: 2 February 2010 Revised: 9 April 2010

Accepted: 10 August 2010 Published: 10 August 2010

\section{References}

1. UNAIDS/WHO: AIDS Epidemic Update 2009.[http://data.unaids.org/pub/ Report/2009/2009_epidemic_update_en.pdf].

2. Afessa B, Green B: Clinical course, prognostic factors, and outcome prediction for HIV patients in the ICU: The PIP (Pulmonary Complications, ICU Support, and Prognostic Factors in Hospitalized Patients with HIV) Study. Chest 2000, 118:138-145.

3. Morris A, Creasman J, Turner J, Luce JM, Watcher RM, Huang L: Intensive care of human immunodeficiency virus-infected patients during the era of highly active antiretroviral therapy. Am J Respir Crit Care Med 2002, 166:262-267.

4. Narasihman M, Posner AJ, DePalo VA, Mayo PH, Rosen MJ: Intensive care in patients with HIV infection in the era of highly active antiretroviral therapy. Chest 2004, 125:1800-1804.

5. Khouli H, Afrasiabi A, Shibli M, Hajal R, Barrett CR, Homel P: Outcome of critically ill human immunodeficiency virus-infected patients in the era of highly active antiretroviral therapy. I Intensive Care Med 2005, 20:327-333.

6. Palacios R, Hidalgo A, Reina C, de la Torre MV, Márquez M, Santos J: Effect of antiretroviral therapy on admissions of HIV-infected patients to an intensive care unit. HIV Med 2006, 7:193-196.

7. Powell K, Davis JL, Morris AM, Chi A, Bensley MR, Huang L: Survival for patients with HIV admitted to the ICU continues to improve in the current era of combination antiretroviral therapy. Chest 2009, 135:11-17.

8. Huang L, Quartin A, Jones D, Havlir DV: Intensive care of patients with HIV infection. N Engl J Med 2006, 355:173-181.

9. Rosen MJ, Narasimhan M: Critical care of immunocompromised patients: human immunodeficiency virus. Crit Care Med 2006, 34:S245-S250.

10. Davaro RE, Thirumalai A: Life-threatening complications of HIV infection. J Intensive Care Med 2007, 22:73-81.
11. Grinsztejn B, Veloso VG, Friedman RK, Moreira RI, Luz PM, Campos DP, Pilotto JH, Cardoso SW, Keruly JC, Moore RD: Early mortality and cause of deaths in patients using HAART in Brazil and the United States. AIDS 2009, 23:2107-2114.

12. Angus DC, Linde-Zwirble WT, Lidicker J, Clermont G, Carcillo J, Pinsky MR: Epidemiology of severe sepsis in the United States: analysis of incidence, outcome, and associated costs of care. Crit Care Med 2001, 29:1303-1310.

13. Martin GS, Mannino DM, Eaton S, Moss M: The epidemiology of sepsis in the United States from 1979 through 2000. N Engl J Med 2003, 348:1546-1554.

14. Annane D, Aegerter $P$, Jars-Guincestre MC, Guidet B: Current epidemiology of septic shock. Am J Resp Crit Care Med 2003, 168:165-172.

15. The EPISEPSIS Study Group: EPISEPSIS: a reappraisal of the epidemiology and outcome of severe sepsis in French intensive care units. Intensive Care Med 2004, 30:580-588.

16. Ballester JCA, Ballester F, Sánchez AG, Quilis AA, Rubio EC, Otero CP: Epidemiology of sepsis in the valencian community (Spain), 1995-2004. Infect Control Hosp Epidemiol 2008, 29:630-634.

17. Blanco J, Muriel-Bombín A, Sagredo V, Taboada F, Gandía F, Tamayo L, Collado J, García-Labattut A, Carriedo D, Valledor M, De Frutos M, López MJ, Caballero A, Guerra J, Alvarez B, Mayo A, Villar J, Grupo de Estudios y Análisis en Cuidados Intensivos: Incidence, organ dysfunction and mortality in severe sepsis: a Spanish multicentre study. Crit Care 2008, 12 R158.

18. Khwannimit B, Bhurayanontachai $R$ : The epidemiology of, and risk factors for, mortality from severe sepsis and septic shock in a tertiary-care university hospital setting. Epidemiol Infect 2009, 137:1333-1341.

19. Beale R, Reinhart K, Brunkhorst FM, Dobb G, Levy M, Martin G, Martin C, Ramsey G, Silva E, Vallet B, Vincent JL, Janes JM, Sarwat S, Williams MD, PROGRESS Advisory Board: Promoting Global Research Excellence in Severe Sepsis (PROGRESS): lessons from an international sepsis registry. Infection 2009, 37:222-232.

20. Mrus JM, Braun LA, Yi MS, Linde-Zwirble WT, Johnston JA: Impact of HIV/ AIDS on care and outcomes of severe sepsis. Crit Care 2005, 9:R623-R630.

21. Soares M, Terzi RGG, Piva JP: End-of-life care in Brazil. Intensive Care Med 2007, 33:1014-1017.

22. Centers for Disease Control and Prevention (CDC): Impact of the expanded AIDS surveillance case definition on AIDS case reporting-United States, first quarter, 1993. MMWR Morb Mortal Wkly Rep 1993, 42:308-311.

23. Le Gall JR, Lemeshow S, Saulnier F: A new Simplified Acute Physiologic Score (SAPS II) based on an European/North American multicenter study. JAMA 1993, 270:2957-2963.

24. Le Gall JR, Neumann A, Hemery F, Bleriot JP, Fulgencio JP, Garrigues B, Gouzes C, Lepage E, Moine P, Villers D: Mortality prediction using SAPS II: an update for French intensive care units. Crit Care 2005, 9:R645-R652.

25. Vincent JL, Moreno R, Takala J, Willatts $\mathrm{S}$, de Mendonça A, Bruining $\mathrm{H}$, Reinhart CK, Suter PM, Thijs LG: The SOFA (Sepsis-related Organ Failure Assessment) score to describe organ dysfunction/failure. Intensive Care Med 1996, 22:707-710.

26. Zubrod CG, Schneiderman M, Frei E III: Appraisal of methods for the study of chemotherapy of cancer in man: comparative therapeutic trial of nitrogen mustard and triethylene thiophosphoramide. J Chron Dis 1960, 11:7-33.

27. Bone RC, Balk RA, Cerra FB, Dellinger RP, Fein AM, Knaus WA, Schein RM, Sibbald WJ: Definitions for sepsis and organ failure and guidelines for the use of innovative therapies in sepsis: the ACCP/SCCM Consensus Conference Committee, American College of Chest Physicians/Society of Critical Care Medicine. Chest 1992, 101:1644-1655.

28. Horan TC, Andrus M, Dudeck MA: CDC/NHSN surveillance definition of health care-associated infection and criteria for specific types of infections in the acute care setting. Am J Infect Control 2008, 36:309-332.

29. R Project. [http://www.r-project.org].

30. Pacheco AG, Tuboi SH, May SB, Moreira LFS, Ramadas L, Nunes EP, Merçon M, Faulhaber JC, Harrison LH, Schechter M: Temporal changes in causes of death among HIV-infected patients in the HAART era in Rio de Janeiro, Brazil. J Acquir Immune Defic Syndr 2009, 51:624-630.

31. Casalino E, Wolff M, Ravaud P, Choquet C, Bruneel F, Regnier B: Impact of HAART advent on admission patterns and survival in HIV-infected patients admitted to an intensive care unit. AIDS 2004, 18:1429-1433. 
32. Angus DC, Wax RS: Epidemiology of sepsis: an update. Crit Care Med 2001, 29:S109-S116.

33. Petrosillo N, Pagani L, Ippolito G, Gruppo HIV e Infezioni Ospedaliere: Nosocomial infections in HIV-positive patients: an overview. Infection 2003, Suppl 2: 28-34.

34. Thyrault M, Gachot B, Chastang C, Souweine B, Timsit JF, Bédos JP, Regnier B, Wolff M: Septic shock in patients with the acquired immunodeficiency syndrome. Intensive Care Med 1997, 23:1018-1023.

35. Rosenberg AL, Seneff MG, Atiyeh $L$, Wagner $R$, Bojanowski $L$, Zimmerman JE: The importance of bacterial sepsis in intensive care unit patients with acquired immunodeficiency syndrome: implications for future care in the age of increasing antiretroviral resistance. Crit Care Med 2001, 29:548-556.

36. Arthur G, Nduba VN, Kariuki SM, Kimari J, Bhatt SM, Gilks CF: Trends in bloodstream infections among human immunodeficiency virus-infected adults admitted to a hospital in Nairobi, Kenya, during the last decade. Clin Infect Dis 2001, 33:248-256.

37. Hung CC, Hsueh PR, Hsieh SM, Liu CJ, Chen MY, Luh KT: Bacteremia and fungemia in patients with advanced human immunodeficiency vírus (HIV) infection in Taiwan. J Formos Med Assoc 1998, 97:690-697.

38. Tumbarello M, Tacconelli E, Donati KG, Citton R, Leone F, Spanu T, Cauda R: HIV-associated bacteremia: how it has changed in the highly active antiretroviral therapy (HAART) era. J Acquir Immune Defic Syndr 2000, 23:145-151.

39. Vidal F, Mensa J, Martínez JA, Almela M, Marco F, Gatell JM, Richart C, Soriano E, Jiménez de Anta MT: Pseudomonas aeruginosa bacteremia in patients infected with human immunodeficiency virus type 1. Eur J Clin Microbiol Infect Dis 1999, 18:473-477.

40. Grinsztejn B, Veloso VG, Pilotto JH, Campos DP, Keruly JC, Moore RD: Comparison of clinical response to initial highly active antiretroviral therapy in the patients in clinical care in the United States and Brazil. $J$ Acquir Immune Defic Syndr 2007, 45:515-520.

41. Schmaltz CA, Santanna FM, Neves SC, Velasque LD, Lourenço MC, Morgado MG, Rolla VC, Lopes GS: Influence of HIV infection on mortality in a cohort of patients treated for tuberculosis in the context of wide access to HAART, in Rio de Janeiro, Brazil. J Acquir Immune Defic Syndr 2009, 52:623-628.

42. Pacheco AG, Durovni B, Cavalcante SC, Lauria LM, Moore RD, Moulton LH, Chaisson RE, Golub JE: AIDS-related tuberculosis in Rio de Janeiro, Brazil. PLoS One 2008, 3:e3132.

43. Waddell RD, Lishimpia K, von Reyn CF, Chintua C, Babooa KS, Kreiswirthb B, Talbotc EA, Karagas MR: Study Group: bacteremia due to Mycobacterium tuberculosis or M. bovis, Bacille Calmette-Guerin (BCG) among HIV positive children and adults in Zambia. AIDS 2001, 15:55-60.

44. Grinsztejn B, Fandinho FC, Veloso VG, João EC, Lourenço MC, Nogueira SA Fonseca LS, Werneck-Barroso E: Mycobacteremia in patients with the acquired immunodeficiency syndrome. Arch Intern Med 1997, 157:2359-2363

45. Croda J, Croda MG, Neves A, Santos SS: Benefit of antiretroviral therapy on survival of human immunodeficiency virus-infected patients admitted to an intensive care unit. Crit Care Med 2009, 37:1605-1611.

46. Vincent B, Timsit JF, Auburtin M, Schortgen F, Bouadma L, Wolff M, Regnier B: Characteristics and outcomes of HIV-infected patients in the ICU: impact of the highly active antiretroviral treatment era. Intensive Care Med 2004, 30:859-866.

47. Davis JL, Morris A, Kallet RH, Powell K, Chi AS, Bensley M, Luce JM, Huang L: Low tidal volume ventilation is associated with reduced mortality in HIV-infected patients with acute lung injury. Thorax 2008, 63:988-993.

48. Silva E, Pedro Mde A, Sogayar AC, Mohovic T, Silva CL, Janiszewski M, Cal RG, de Sousa EF, Abe TP, de Andrade J, de Matos JD, Rezende E, Assunção M, Avezum A, Rocha PC, de Matos GF, Bento AM, Corrêa AD, Vieira PC, Knobel E, Brazilian Sepsis Epidemiological Study: Brazilian Sepsis Epidemiological Study (BASES study). Crit Care 2004, 8:R251-R260.

49. Sales-Júnior JA, David CM, Hatum R, Souza PC, Japiassú A, Pinheiro CT, Friedman G, Silva OB, Dias MD, Koterba E, Dias FS, Piras C, Luiz RR: An epidemiological study of sepsis in intensive care units. Sepsis Brazil Study. Rev Bras Ter Intens 2006, 18:9-17.

50. Dellinger RP, Levy MM, Carlet JM, Bion J, Parker MM, Jaeschke R, Reinhart K, Angus DC, Brun-Buisson C, Beale R, Calandra T, Dhainaut JF, Gerlach H, Harvey M, Marini JJ, Marshall J, Ranieri M, Ramsay G, Sevransky J, Thompson BT, Townsend S, Vender JS, Zimmerman JL, Vincent $J \mathrm{~L}$,
International Surviving Sepsis Campaign Guidelines Committee; American Association of Critical-Care Nurses; American College of Chest Physicians; American College of Emergency Physicians; Canadian Critical Care Society; European Society of Clinical Microbiology and Infectious Diseases, et al: Surviving Sepsis Campaign: international guidelines for management of severe sepsis and septic shock: 2008. Crit Care Med 2008, 36:296-327.

51. Becker JU, Theodosis C, Jacob ST, Wira CR, Groce NE: Surviving sepsis in low-income and middle-income countries: new directions for care and research. Lancet Infect Dis 2009, 9:577-582.

52. Cheng AC, West TE, Limmathurotsakul D, Peacock SJ: Strategies to reduce mortality from bacterial sepsis in adults in developing countries. PLOS Med 2008, 5:e175.

53. Bozza FA, Salluh Jl: An urban perspective on sepsis in developing countries. Lancet Infect Dis 2010, 10:290-291.

doi:10.1186/cc9221

Cite this article as: Japiassú et al:: Sepsis is a major determinant of outcome in critically ill HIV/AIDS patients. Critical Care 2010 14:R152.

\section{Submit your next manuscript to BioMed Central and take full advantage of:}

- Convenient online submission

- Thorough peer review

- No space constraints or color figure charges

- Immediate publication on acceptance

- Inclusion in PubMed, CAS, Scopus and Google Scholar

- Research which is freely available for redistribution

Submit your manuscript at www.biomedcentral.com/submit
C) Biomed Central 